\title{
Assess Nursing Practice Regarding Safety Measures on Mechanically Ventilated Patients.
}

\author{
Suzan Shawky Botros ${ }^{1}$, Mona Aly Mohamed ${ }^{2} \&$ Naglaa Ahamed Ahamed ${ }^{3}$. \\ 1. Specialist nursing at Heart Hospital, Assuit University, Egypt. \\ 2. Assistant professor of critical care nursing, faculty of nursing Assuit university, Egypt. \\ 3. Lecturer of critical care nursing, faculty of nursing Assuit university, Egypt.
}

\begin{abstract}
Background: Nurse had vital role in implementing safety measures for patient connected to mechanical ventilator in critically ill patient. Aim of the study: was to assess nursing practice regarding safety measures on mechanically ventilated patients Research design: A descriptive research design was utilized in this study, the study was conducted in the intensive coronary care units at Assuit university heart hospital. A convenient sample: All available nurses 30 of nursing staff that working in mentioned setting. Tools: Two tools: questionnaire and observational checklist. Results: ; More than half of nurses were in age group less than 25 years . Concerning their educational level, $53.3 \%$ of the nurse held nursing institute. $60.0 \%$ of nurse had work experience less than 5 years. Total nurses level of practice was found that three of fifth of nurses $60.0 \%$ were low, $30.0 \%$ of them were moderate and $10.0 \%$ were high. Conclusion: The general score of nurses complete nursing practice regarding safety measures on mechanical ventilation was to be low practice. Recommendations: Nurses need in -service training programs, periodic monitoring of nurses practices and effective training for new nurses.
\end{abstract}

\section{Keywords: Nursing practice, Safety measures \& Mechanically Ventilated Patients.}

\section{Introduction}

Mechanical ventilation is a life-saving treatment to support patient when they are unable to oxygenate and ventilate on their own. The skills required by health teams, in particular of nurses, to manage a ventilation unit are typically standardized to ensure safe handling of ventilation equipment and for proper management of patients during their course of care (Mohamed, et al., 2017).

Goals of mechanical ventilation improve pulmonary gas exchange, relieve respiratory distress ,decrease work of breathing, permit lung healing, reverse respiratory muscle fatigue, , avoid complications (Romero, et al., 2015).

Safety measures refers to using measures for patient safety to protected from harm or other non -desirable outcome and achieve patient safety through use of maximum sterile barriers while placing central venous catheters to prevent infections or any invasive procedure to patient, doing hand washing, use of pressure-relieving bedding materials to prevent pressure ulcers, continuous aspiration of subglottic secretions to prevent ventilator-associated pneumonia and any measure that achieve safety and prevention of harm to patients (Parampreet, et al., 2019).

Suctioning of ventilated patients in general, all ventilated patients need regular suctioning. Since these patients are not able to expectorate their secretions which often collect in the airways, become viscous, and lead to respiratory distress. When suctioning patients on a ventilator, look and listen to the chest of the patient. If it is clear and has no distress, suctioning is not required. Suctioning is based on need and should not be performed on a schedule. If suctioning is appropriate, hyperoxygenate the patient for a few minutes before initiating suctioning. This is vital since suctioning can quickly lead to hypoxia. The suctioning procedure should only last for 10 seconds and pay attention to the pulse oximetry (Carruthers, et al., 2018).

Ventilator initiation is all manufacturers of ventilators highly recommend a pre-operational check prior to the use of the ventilator on a patient. This precheck is designed to check the confirm the functioning of the components, integrity of the ventilator circuit, , the tubing and humidifier system. The precheck is usually done at the time of the humidifier or circuit set up. In addition, any time the circuit is modified or changed, a precheck must be done (Richard, et al., 2016).

Using effective infection control measures such as education and training of healthcare workers, high compliance with alcohol-based hand rubbing as the main measure for hand hygiene, cleaning, disinfection, and sterilization of reusable components and appropriate maintenance of equipment, use of gloves when handling respiratory secretions, use of sterile water for rinsing reusable equipment (Guilherme \& Martin, 2017)

Pressure area care is ventilated patients, especially those who are sedated, lose the ability to reposition themselves placing them at risk of developing pressure sores. These most commonly develop where skin covers a bony prominence. 
Preventative measures include repositioning and turning the patient every 2-4 hours, , frequent inspection of pressure areas with early intervention when skin damage is found and the use of pressure relieving beds and mattresses (Xiao \& Fan, 2015).

Mechanical ventilators are sophisticated and require training to ensure positive outcomes. Inappropriate setting changes, changing settings without appropriate orders, failure to change alarms, and failure to communicate changes to the medical team can result in poor patient outcomes. This activity is intended to monitor health professionals to ensure that all personnel trained are trained to set up, install, and make appropriate adjustments to mechanical ventilation. An interdisciplinary approach with communication between all members of the healthcare team will result in produce the best outcomes and the safest delivery of care.( Lesley $\boldsymbol{\&}$ Sandeep , 2019)

Weaning from mechanical ventilation is the process of decreasing the amount of ventilator support, with the patient gradually assuming a greater proportion of the overall work of ventilation. weaning and extubation at the earliest possible time are among the a priori goals of mechanical respiratory support. In addition to the obvious goal of reducing ventilatorinduced lung injury, early weaning will reduce the risk of nosocomial sepsis, minimize the development of oral aversion with subsequent feeding difficulties, reduce patient discomfort and need for sedation and facilitate parental bonding and developmentally appropriate care. (Guilherme \& Martin, 2017)

\section{Significance of the Study}

Statistics in the coronary intensive coronary care unit at Assuit University Hospital in year 2016 revealed that the number of admitted ventilated patients were 206 patient and about 60 patients had experenced complication from intubation of mechanical ventilation. (Assiut University Hospital record 2017).

\section{Aim of the study}

The aim of this study is to assess nursing practice regarding safety measures on mechanically ventilated patients.

\section{Operational definition}

Safety measures is an important nursing care to the patient to protected from harm or other non desirable outcome that connected to mechanical ventilator.

\section{Research question}

What is nurses' level of practice regarding safety measures of mechanically ventilated patients at Assuit university heart hospital?

\section{Research Design}

A descriptive research design was adopted to meet the aim of this study

\section{Setting}

The study was conducted at Assuit university heart hospital in the coronary intensive care units is located in the second flour; it consists of three rooms with a total bed capacity of 16 beds and there are 7 of mechanical ventilator.

\section{Study Subjects}

A convenience sample of all available nurses (30) agreed to participate in the study and working in the mentioned setting.

\section{Tools}

Two tools was developed by the researcher based on extensive review of related literatures (Lesley $\boldsymbol{\&}$ Sandeep , 2019) \& ( Gad N, 2016) divided into:

\section{Tool I: Nurses' assessment questionnaire}

This tool was developed to assess the nurses' demographic data through direct question consist of 6 question such as: age, residence, education ,courses,years of experience and marital status.

\section{Tool II: Observational checklist}

This tool was developed by researcher after reviewing national and international literature based related critical nursing procedures to assess nursing practices in form of structured observational checklist which includes the following procedures:

- Endotracheal suction appropriately (Mwakanyanga, et al., 2018) includes (17) items

- Safety preparation for intubated patient (Lindgren \& Ames, 2015) includes (12) items .

- Safety preparation for mechanical ventilator .

( Lesley \& Sandeep, 2019) includes (9) items .

- Infection control measures (Gad, 2016) includes (10) items .

- Weaning the patient from the ventilator appropriately (Khalil, et al., 2018) includes (7) items

- Obtaining an arterial blood specimen for blood gas analysis (Hennessey \& Japp, 2016) includes (14) items

- Assisting a patient with turning in bed (Powers, 2016) includes (14) items

Operational design

It includes preparatory, implementation and evaluation phase.

preparatory phase

After reviewing the recent related literatures, study tools were developed. 


\section{Content validity}

The tools was revised by 7 experts in the nursing field to test content validity, clarity, feasibility and the necessary modification was done.

\section{Reliability of the tools}

The overall reliability of the tools was tested using alpha Cronbach's test (0.905) for the pilot study results.

\section{Pilot study}

A pilot study was done on 6 nursing who will not be included in the study, to test the applicability of the study tools and the necessary modification was done.

\section{Ethical consideration}

Informed consent was obtained from the nurses, research proposal was approved from Ethical Committee in the Faculty of Nursing, there is no risk for study subject during application of the research, the study was follow common ethical principles in clinical research, confidentiality and anonymity was assured ,study subject have the right to refuse to participate and or withdraw from the study without any rational any time and privacy was considered during collection of data.

\section{Implementation phase}

- An official permission from the Dean of faculty of nursing to conduct this study was delivered to the hospital authorities at Assuit university heart hospital and approval to conduct this study was obtained after explanation of the aims of study.
- Sampling was started from the first of jennoury 2018 until the end of feberoury 2019 ,due to decrease number of patients on mechanical ventilator.

- An observational checklist was carried out to the nurses during their working in the morning and afternoon shift each observation lasted for 20 minutes and will be carried without the nurses attention by using tool II to assess the level of performance during nurses' procedure.

- Scoring system of nurses ' observational checklist tool (Amr \& Mohsen, 2017): each items was observed and categorized and scored into two grade for done correctly, one grade for done incorrect and zero for not done and categorized as:

- Less than $65 \%$ was regarded low level of skills.

- Equal or above $65 \%$ until $75 \%$ was regarded moderate level of skills.

- Above 75\% was regarded high level of skills.

Statistical analysis

Data were computerized and analyzed by computer program SPSS (ver.20), data of obtained result were tabulated in the form of frequency using mean $\pm \mathrm{SD}$, number and percentage and Chi - square test .Statistical significant differences were considered Pvalue is considered non-significant when $\mathrm{P}>0.05$ and significant when $\mathrm{p}<0.05$.

\section{Results}

Table (1): Distribution of Socio demographic data about nurses under the study group $(\mathbf{n}=30)$.

\begin{tabular}{|c|c|c|}
\hline Item & No & $\%$ \\
\hline \multicolumn{3}{|l|}{ Age group } \\
\hline$>25$ years old & 19 & 63.3 \\
\hline$<25$ years old & 11 & 36.7 \\
\hline Mean \pm SD(range) & \multicolumn{2}{|c|}{$25.7 \pm 1.7(22-30)$} \\
\hline \multicolumn{3}{|l|}{ Residence } \\
\hline Rural & 14 & 46.7 \\
\hline Urban & 16 & 53.3 \\
\hline \multicolumn{3}{|l|}{ Education } \\
\hline Nursing secondary school & 14 & 46.7 \\
\hline Technical nursing institute & 16 & 53.3 \\
\hline \multicolumn{3}{|l|}{ Experience } \\
\hline$>5$ years & 18 & 60.0 \\
\hline$<5$ years & 12 & 40.0 \\
\hline \multicolumn{3}{|c|}{ Training courses about safety measures } \\
\hline Yes & 2 & 6.7 \\
\hline No & 28 & 93.3 \\
\hline \multicolumn{3}{|l|}{ Marital Status } \\
\hline Single & 6 & 20.0 \\
\hline Married & 24 & 80.0 \\
\hline
\end{tabular}


Table (2): Distribution of nurses practice checklist for endotracheal suctioning appropriately under the study group $(\mathbf{n}=\mathbf{3 0})$.

\begin{tabular}{|l|c|c|c|c|c|c|}
\hline \multirow{2}{*}{ Item } & \multicolumn{2}{|c|}{ Not done } & \multicolumn{2}{c|}{ Done Incorrect } & \multicolumn{2}{c|}{ Done Correct } \\
\cline { 2 - 7 } & No & $\%$ & No & $\%$ & No & \% \\
\hline prepare equipment to the bedside. & 0 & 0.0 & 14 & 46.7 & 16 & 53.3 \\
\hline perform hand hygiene and maintain patient privacy & 0 & 0.0 & 30 & 100.0 & 0 & 0.0 \\
\hline Determine the need for suctioning. & 0 & 0.0 & 0 & 0.0 & 30 & 100.0 \\
\hline Adjust the bed to a comfortable working position. & 0 & 0.0 & 12 & 40.0 & 18 & 60.0 \\
\hline Place towel or waterproof pad across the patient's chest. & 8 & 26.7 & 0 & 0.0 & 22 & 73.3 \\
\hline Turn Suction to appropriate pressure & 0 & 0.0 & 30 & 100.0 & 0 & 0.0 \\
\hline Open sterile suction package using aseptic technique. & 0 & 0.0 & 30 & 100.0 & 0 & 0.0 \\
\hline Put on sterile gloves. & 0 & 0.0 & 0 & 0.0 & 30 & 100.0 \\
\hline With dominant gloved hand, pick up sterile catheter. & 0 & 0.0 & 19 & 63.3 & 11 & 36.7 \\
\hline Hyperventilate the patient using your nondominant hand & 0 & 0.0 & 11 & 36.7 & 19 & 63.3 \\
\hline Remove the manual resuscitation bag. & 0 & 0.0 & 11 & 36.7 & 19 & 63.3 \\
\hline Apply suction and gently rotate the catheter. & 0 & 0.0 & 20 & 66.7 & 10 & 33.3 \\
\hline Hyperventilate the patient . & 0 & 0.0 & 11 & 36.7 & 19 & 63.3 \\
\hline Flush catheter with saline. & 0 & 0.0 & 0 & 0.0 & 30 & 100.0 \\
\hline Allow at least a 30-second to 1-minute interval & 8 & 26.7 & 22 & 73.3 & 0 & 0.0 \\
\hline When suctioning is completed remove gloves. & 0 & 0.0 & 30 & 100.0 & 0 & 0.0 \\
\hline Reassess the patient's respiratory status. & 15 & 50.0 & 9 & 30.0 & 6 & 20.0 \\
\hline
\end{tabular}

Table (3): Distribution of nurses practice checklist for Safety preparation of intubated patient and ventilator under the study group $(\mathbf{n}=30)$.

\begin{tabular}{|c|c|c|c|c|c|c|}
\hline \multirow{2}{*}{ Item } & \multicolumn{2}{|c|}{ Not done } & \multicolumn{2}{|c|}{ Done Incorrect } & \multicolumn{2}{|c|}{ Done Correct } \\
\hline & No & $\%$ & No & $\%$ & No & $\%$ \\
\hline \multicolumn{7}{|l|}{ For patient } \\
\hline Ensure that ETT is connected . & 0 & 0.0 & 0 & 0.0 & 30 & 100.0 \\
\hline Remove old tape and ties & 0 & 0.0 & 2 & 6.7 & 28 & 93.3 \\
\hline Reconfirm tube placement. & 23 & 76.7 & 6 & 20.0 & 1 & 3.3 \\
\hline Head of bed elevated at $30^{\circ}$ or greater. & 7 & 23.3 & 8 & 26.7 & 15 & 50.0 \\
\hline Provide frequent mouth care: mouth care every 2 hours. & 9 & 30.0 & 3 & 10.0 & 18 & 60.0 \\
\hline Turn and reposition the patient at least every 2 hour. & 16 & 53.3 & 0 & 0.0 & 14 & 46.7 \\
\hline Patient should be kept nil by mouth (NPO) while intubated. & 14 & 46.7 & 0 & 0.0 & 16 & 53.3 \\
\hline Contuous monitoring for $\mathrm{ABG}$ & 0 & 0.0 & 0 & 0.0 & 30 & 100.0 \\
\hline Use aseptic teachaniqe in all suctioning procedure. & 19 & 63.3 & 10 & 33.3 & 1 & 3.3 \\
\hline Check for patient causes ventilator alarm & 30 & 100.0 & 0 & 0.0 & 0 & 0.0 \\
\hline Promote adequate fluid and nutritional intake & 0 & 0.0 & 30 & 100.0 & 0 & 0.0 \\
\hline Listen the air entry, breath sound. & 10 & 33.3 & 15 & 50.0 & 5 & 16.7 \\
\hline \multicolumn{7}{|l|}{ For ventilator equipment } \\
\hline Changing ventilator tubing per hospital policy & 16 & 53.3 & 0 & 0.0 & 14 & 46.7 \\
\hline Ensuring that the ventilator tubing is free of water. & 10 & 33.3 & 0 & 0.0 & 20 & 66.7 \\
\hline Positioning the ventilator tubing to avoid kinking & 9 & 30.0 & 0 & 0.0 & 21 & 70.0 \\
\hline \multicolumn{7}{|l|}{ For ventilator setting } \\
\hline Routinely monitor ventilator setting. & 0 & 0.0 & 0 & 0.0 & 30 & 100.0 \\
\hline Check all ventilator connection regularly & 0 & 0.0 & 20 & 66.7 & 10 & 33.3 \\
\hline Check Fio2, Tidal volume( VT),PEEP. & 0 & 0.0 & 0 & 0.0 & 30 & 100.0 \\
\hline Check mode of ventilator (AlC, SIMV) & 0 & 0.0 & 0 & 0.0 & 30 & 100.0 \\
\hline Monitor alarm sound ,examine the patient . & 30 & 100.0 & 0 & 0.0 & 0 & 0.0 \\
\hline check for mechanical causes of ventilator alarm. & 30 & 100.0 & 0 & 0.0 & 0 & 0.0 \\
\hline
\end{tabular}




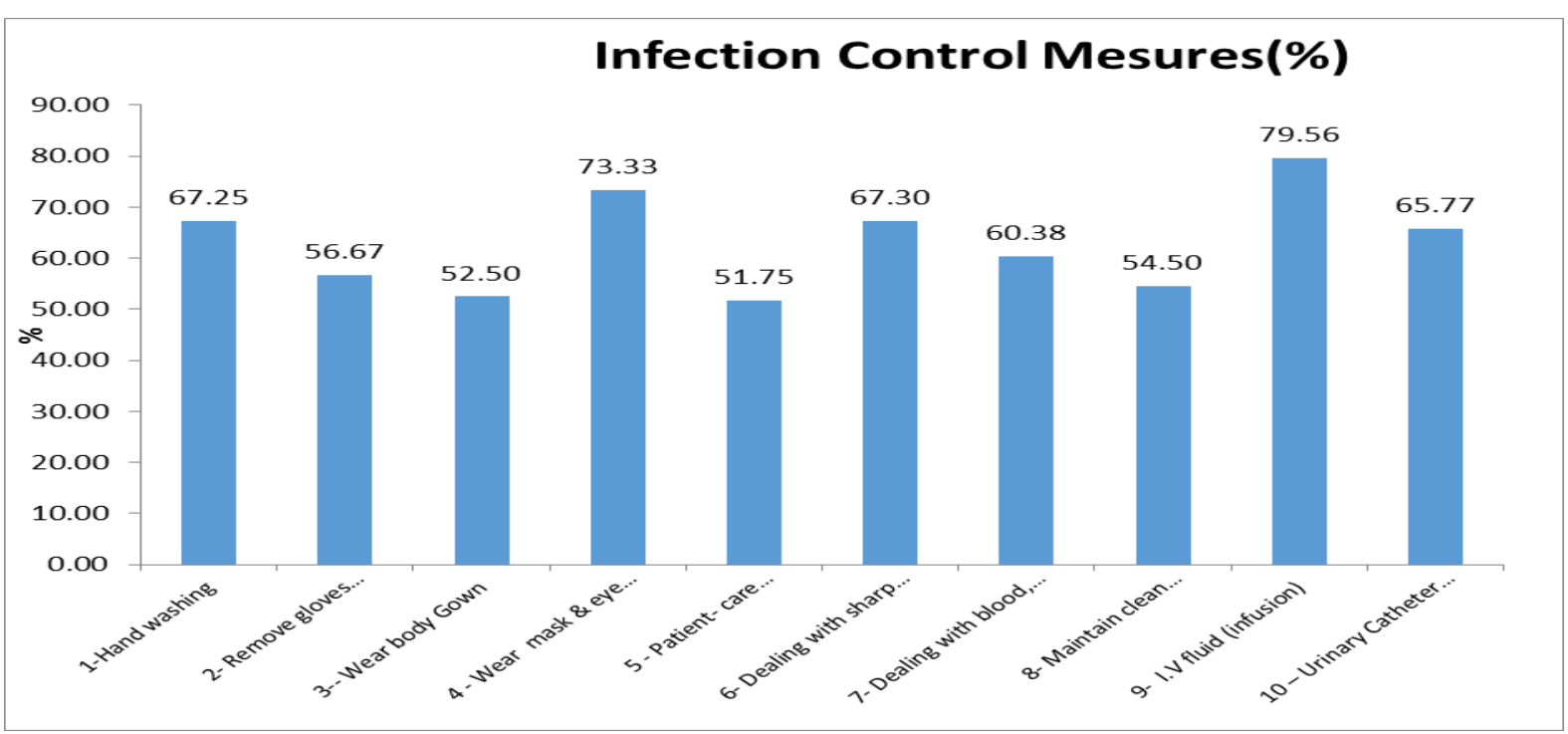

Figure( 1): Distribution of nurses practice checklist about infection control measures under the study group (n=30)

Table (4): Distribution of nurses practice checklist of weaning from mechanical ventilator under the study group (n=30).

\begin{tabular}{|l|c|c|c|c|c|c|}
\hline \multirow{2}{*}{ Item } & \multicolumn{2}{c|}{ Not done } & \multicolumn{2}{c|}{ Done Incorrect } & \multicolumn{2}{c|}{ Done Correct } \\
\cline { 2 - 7 } & No & $\boldsymbol{\%}$ & No & $\%$ & No & $\%$ \\
\hline Determine readiness for weaning & 0 & 0.0 & 12 & 40.0 & 18 & 60.0 \\
\hline Obtain weaning parameters as doctor order. & 0 & 0.0 & 0 & 0.0 & 30 & 100.0 \\
\hline Plan to initiate early in the day and explain procedure. & 5 & 16.7 & 0 & 0.0 & 25 & 83.3 \\
\hline Obtain baseline vital signs and use semi-Fowler's position & 7 & 23.3 & 13 & 43.3 & 10 & 33.3 \\
\hline Initiate weaning according to desired mode & 1 & 3.3 & 0 & 0.0 & 29 & 96.7 \\
\hline Suction when necessary and administer bronchodilator & 15 & 50.0 & 0 & 0.0 & 15 & 50.0 \\
\hline Provide support to the patient & 0 & 0.0 & 30 & 100.0 & 0 & 0.0 \\
\hline
\end{tabular}

Table (5): Distribution of nurses practice checklist of obtaining an arterial blood specimen for Blood Gas Analysis under the study group $(n=30)$.

\begin{tabular}{|l|c|c|c|c|c|c|}
\hline \multicolumn{1}{|c|}{ Item } & \multicolumn{2}{c|}{ Not done } & \multicolumn{2}{c|}{ Done Incorrect } & Done Correct \\
\cline { 2 - 6 } & No & $\boldsymbol{\%}$ & $\mathbf{N o}$ & $\boldsymbol{\%}$ & No & $\boldsymbol{\%}$ \\
\hline Assess factors that influence ABG measurement & 6 & 20.0 & 0 & 0.0 & 24 & 80.0 \\
\hline Record patient inspired oxygen concentration. & 3 & 10.0 & 0 & 0.0 & 27 & 90.0 \\
\hline Assess patient's temperature, amount of oxygen . & 2 & 6.7 & 0 & 0.0 & 28 & 93.3 \\
\hline Assemble equipment on over bed table . & 0 & 0.0 & 0 & 0.0 & 30 & 100.0 \\
\hline If puncture the redial artery, perform Allen's test. & 30 & 100.0 & 0 & 0.0 & 0 & 0.0 \\
\hline $\begin{array}{l}\text { a. the radial side, places a small towel roll under the patient } \\
\text { b. For brachial artery, hyperextend the arm } \\
\text { c. For femoral artery, rotate the leg slightly outward }\end{array}$ & 30 & 100.0 & 0 & 0.0 & 0 & 0.0 \\
\hline Put on non-sterile gloves. Locate the radial artery . & & & & & & \\
\hline Clean the patient's skin at the puncture site. & 4 & 13.3 & 12 & 40.0 & 14 & 46.7 \\
\hline The needle is at a 45 to 60 degree angle. & 0 & 0.0 & 13 & 43.3 & 17 & 56.7 \\
\hline After blood is obtained, withdraw needle . & 0 & 0.0 & 11 & 36.7 & 19 & 63.3 \\
\hline Remove air bubbles from syringe and needle. & 0 & 0.0 & 0 & 0.0 & 30 & 100.0 \\
\hline Roll the syringe gently between both hands . & 5 & 16.7 & 25 & 83.3 & 0 & 0.0 \\
\hline Label specimen, and send to laboratory immediately. & 0 & 0.0 & 0 & 0.0 & 30 & 100.0 \\
\hline documentation: ABG result & 0 & 0.0 & 0 & 0.0 & 30 & 100.0 \\
\hline
\end{tabular}


Table (6): Distribution of nurses practice checklist of assisting a patient with turning in bed under the study group $(\mathbf{n}=30)$.

\begin{tabular}{|l|c|c|c|c|c|c|}
\hline \multicolumn{1}{|c|}{ Item } & \multicolumn{2}{c|}{ Not done } & \multicolumn{2}{c|}{ Done Incorrect } & \multicolumn{2}{c|}{ Done Correct } \\
\cline { 2 - 8 } & No & $\mathbf{\%}$ & No & \% & No & $\%$ \\
\hline Review the medical order . & 0 & 0.0 & 0 & 0.0 & 30 & 100.0 \\
\hline Gather any positioning aids or supports. & 0 & 0.0 & 0 & 0.0 & 30 & 100.0 \\
\hline Perform hand hyagiene.put on PPE,as indicated. & 9 & 30.0 & 0 & 0.0 & 21 & 70.0 \\
\hline Identify, explain the procedure to the patient. & 10 & 33.3 & 0 & 0.0 & 20 & 66.7 \\
\hline Maintain privacy. & 9 & 30.0 & 0 & 0.0 & 21 & 70.0 \\
\hline If not in place, position sheet under patient. & 0 & 0.0 & 0 & 0.0 & 30 & 100.0 \\
\hline Using sheet, move the patient to the edge . & 19 & 63.3 & 0 & 0.0 & 11 & 36.7 \\
\hline Place the patient's arms across his or her chest. & 0 & 0.0 & 30 & 100.0 & 0 & 0.0 \\
\hline If available ,activate the bed turn mechanism. & 30 & 100.0 & 0 & 0.0 & 0 & 0.0 \\
\hline $\begin{array}{l}\text { The nurse on the side of the bed toward which the patient is } \\
\text { turning should stand opposite the patient's center. }\end{array}$ & 0 & 0.0 & 30 & 100.0 & 0 & 0.0 \\
\hline Use a pillow or other support behind the patient's & 13 & 43.3 & 0 & 0.0 & 17 & 56.7 \\
\hline Make the patient comfortable . & 5 & 16.7 & 0 & 0.0 & 25 & 83.3 \\
\hline Place the bed in the lowest position. & 1 & 3.3 & 0 & 0.0 & 29 & 96.7 \\
\hline Remove gloves and other PPE. & 9 & 30.0 & 0 & 0.0 & 21 & 70.0 \\
\hline
\end{tabular}

Table (7): Distribution of total nurses practice regarding safety measures for patients with mechanical ventilation $(\mathbf{n}=\mathbf{3 0})$.

\begin{tabular}{|l|c|c|}
\hline \multicolumn{1}{|c|}{ Item } & No & \% \\
\hline 1-Endotracheal suctioning & 34 & $69.51 \%$ moderate \\
\hline $\begin{array}{l}\text { 2-Safety preparation for intubated patient and } \\
\text { ventilator }\end{array}$ & 42 & $57.14 \%$ \\
\hline 3- Infection control measures & 106 & $65.16 \%$ moderate \\
\hline 4-Weaning from mechanical ventilation & 14 & $73.57 \%$ moderate \\
\hline $\begin{array}{l}\text { 5-Obtaining an arterial blood specimen for } \\
\text { Blood Gas Analysis }\end{array}$ & 28 & $70.12 \%$ moderate \\
\hline 6-Assessting a patient with turning in bed & 28 & $70.12 \%$ moderate \\
\hline
\end{tabular}




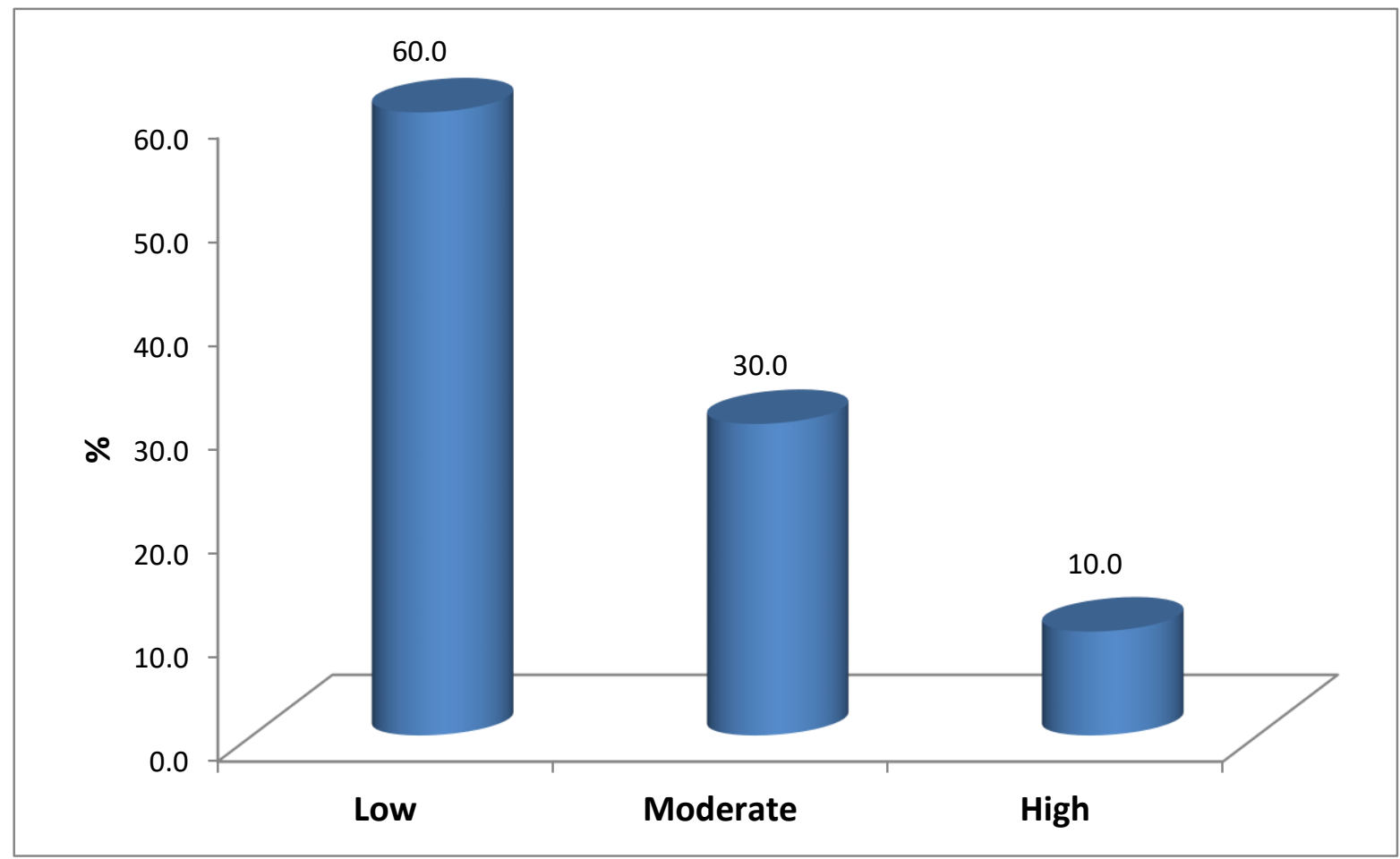

Figure (2): Distribution of total level of practice nurses regarding safety measures for patients with mechanical ventilation $(\mathrm{n}=\mathbf{3 0})$

Table (8): Distribution of relationship between nurses total practice and their socio demographic data (n=30).

\begin{tabular}{|c|c|c|c|c|}
\hline & \multicolumn{3}{|c|}{ Total Practice } & \multirow{2}{*}{ P. value } \\
\hline & $\mathbf{N}$ & Mean \pm SD & Range & \\
\hline \multicolumn{5}{|l|}{ Age group } \\
\hline Less than 25 & 19 & $224.84 \pm 3.85$ & $214-230$ & \multirow{2}{*}{0.062} \\
\hline More than 25 & 11 & $233.64 \pm 19.27$ & $215-265$ & \\
\hline \multicolumn{5}{|l|}{ Residence } \\
\hline Rural & 14 & $225.14 \pm 3.55$ & $221-230$ & \multirow{2}{*}{0.236} \\
\hline Urban & 16 & $230.63 \pm 16.59$ & $214-265$ & \\
\hline \multicolumn{5}{|l|}{ education Level } \\
\hline Diploma Nursing & 14 & $224.71 \pm 1.9$ & $222-228$ & \multirow{2}{*}{0.173} \\
\hline technical nursing institute & 16 & $231 \pm 16.69$ & $214-265$ & \\
\hline \multicolumn{5}{|l|}{ experience year } \\
\hline Less than 5 years & 18 & $225.78 \pm 3.06$ & $221-230$ & \multirow{2}{*}{0.225} \\
\hline More than 5 years & 12 & $231.5 \pm 19.36$ & $214-265$ & \\
\hline \multicolumn{5}{|l|}{ Training courses } \\
\hline Yes & 2 & $246 \pm 26.87$ & $227-265$ & \multirow{2}{*}{$0.033 *$} \\
\hline No & 28 & $226.79 \pm 10.73$ & $214-262$ & \\
\hline \multicolumn{5}{|l|}{ marital Status } \\
\hline Single & 6 & $222.83 \pm 1.47$ & $221-224$ & \multirow{2}{*}{0.258} \\
\hline Married & 24 & $229.38 \pm 13.68$ & $214-265$ & \\
\hline
\end{tabular}

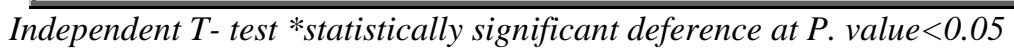


Table (1): This table shows that; $(63.3 \%)$ of nurses were in age less than 25 years , $(36.7 \%)$ of nurses were less than 25 years . Concerning their educational level, $(53.3 \%)$ of the nurse held nursing institute, $(46.7 \%)$ of the nurse held nursing secondary school . Moreover, $(60.0 \%)$ of nurse had work experience less than 5 years, $(40.0 \%)$ of them More than 5 years .

Table (2): This table shows that; distribution of nurses practice regarding endotracheal suctioning appropriately in routine care. It was found that all of the nurses $(100.0 \%)$ determine the need for suctioning. All nurses $(100.0 \%)$ turn Suction to appropriate pressure in correctly .More than one quarter $(26.7 \%)$ not place towel or waterproof pad across the patient's chest and not allow at least a 30second to 1-minute interval.

Table (3): This table shows that; distribution of nurses practice regarding safety preparation of intubated patient and ventilator. It was found that all of the nurses $(100.0 \%)$ ensure that ETT is connected, monitoring for $\mathrm{ABG}$ and check Fio2, Tidal volume( VT), PEEP ,mode of ventilator (AIC, SIMV).More than two third of them $(70.0 \%)$ positioning the ventilator tubing to avoid kinking incorrectely.All of the nurses $(100.0 \%)$ not monitor alarm sound and not examine the patient check for mechanical causes of ventilator alarm.

Figure (1): This figure shows that; distribution of nurses practice regarding infection control. It was found that more than two thirds of nurses $(67.25 \%)$ doing hand washing . More than half of the nurses $(56.67 \%)$ remove gloves promptly. Half of the nurses $(52.50 \%)$ wear body gown during procedures . $(73.33 \%)$ of them wear mask \& eye protection. Half of the nurses $(51.75 \%)$ that doing care of patient equipment. Three quarter of nurses $(67.30 \%)$ dealing with sharp objects. $\operatorname{Nearly}(60.30 \%)$ of the nurses dealing with blood ,body secretion \&fluids. (54.50\%) of that maintain clean environment. Three quarter of nurses(79.56\%)doing procedure of I.V fluid. $(65.77 \%)$ of nurses doing urinary catheter insertion.

Table (4): This table shows that; distribution of nurses practice regarding of weaning from mechanical ventilation .It was found that more than one half of nurses $(60.0 \%)$ determine readiness for weaning. Majority of them $(83.3 \%)$ plan to initiate early in the day and explain procedure. Half of the nurses $(50.0 \%)$ not doing suction when necessary and administer bronchodilator.

Table (5): This table shows that; distribution of nurses practice regarding of obtaining an arterial blood specimen for blood gas analysis. It was found all of the nurses $(100.0 \%)$ not perform Allen's test .Less than half of nurses $(46.7 \%)$ clean the patient's skin at the puncture site. $(56.7 \%)$ of nurses put the needle in a 45 to 60 degree angle. All of the nurses $(100.0 \%)$ remove air bubbles from syringe and needle Nearly one fifth of nurses $(16.7 \%)$ not roll the syringe gently between both hands.

Table (6): This table shows that; distribution of nurses practice regarding of assisting a patient with turning in bed .It was found that more than two third of them(70.0\%) perform hand hyagiene.put on PPE. All of the nurses (100.0\%)position sheet under patient. More than half of the nurses $(63.3 \%)$ not using sheet and not move the patient to the edge. All of the nurses $(100.0 \%)$ place the patient's arms across his or her chest its done incorrectly. ( $56.7 \%$ )of nurses use a pillow or other support behind the patient's .

Table (7): This table shows total nurses practice that; checklist (1) endotracheal suctioning appropriately with nurses level moderate $(69.51 \%)$.checklist(2)Safety preparation for intubated patient and ventilator with nurses level Low $(57.13 \%)$. Checklist (3) how prevent infection with nurses level moderate(65.16\%). checklist(4)weaning from mechanical ventilation with nurses level moderate (73.57\%). checklist(5)Obtaining an arterial blood specimen for Blood Gas Analysis with nurses level moderate(70.12\%). checklist(6)assessing a patient with turning in bed with nurses level moderate $(70.12 \%)$.

Figure (2): Illustrate total nurses level of practice of nurses: It was found that more than half of nurses $(60.0 \%)$ were low, $(30.0 \%)$ of them were moderate and $(10.0 \%)$ were high

Table (8): Show the distribution of relationship between nurses total practice and their socio demographic data. It was found that there were no statistical differences except in nurses that not taking training courses were Mean \pm SD of $(226.79 \pm 10.73)$ and nurses taking training courses were Mean \pm SD of(246 \pm 26.87$)$.

\section{Discussion}

The care of the mechanically ventilated patient is at the core of a nurse's clinical practice in the Intensive Care Unit (ICU). The mechanically ventilated patient presents many safety measures for the critical care nurse (Hetland, et al., 2018). Nurses are constantly present at the patient's bedside, so they are the primary healthcare professional responsible for monitoring the patient's respiratory status. They are expected to keep an eye on any equipment required by the patients, including ventilators and 
monitoring equipment, and to respond to monitor alarms ( Osti, et al., 2017)

Based on the results of this study, the mean age of the study nurses' group are less than 25 years old about two thirds of them and this result is approved by the study done by (Shehab, et al., 2018) who noticed that the majority of ICU nursing staff was less than 25 yrs.

Concerning the level of education of the study nurses, the present study showed that the whole nursing staff in the field of study were diploma nurse and technical nurses and this result disagree with (Bayoumi \& Mahmoud, 2017) who reported that about one third of the staff nurses were bachelor degree in nursing. The current study revealed that the majority of the study nurses had five years of experience or less than five years and this result is in the same line with (Mwakanyanga, et al., 2018) who noticed that about half of the ICU staff nurses had less than five years of experience in the intensive care field and about one tenth had more than 10 years of experience.

According to intensive care specialty course attendance, the present study reflected that the about all of them didn't attend any courses and this result disagree with (Hakim, 2015) who said that about half of the nurses participate in intensive care courses.

Regarding to the practice checklist prior to endotracheal suctioning, the present study illustrate that all of the staff nurse performs hand hygiene but done incorrectly, two thirds of them hyperventilate the patients prior to suctioning correctly and this result agree with (Mwakanyanga, et al., 2018) who noticed results closed to the results of this study. As regard to the actions performed during suctioning, the total number of nurses adjust the aspirator pressure incorrectly, two thirds of them not rotating the catheter of suction during procedures and one third of the study nurses not made interval in between the suction cycle and this result is in contrast with the study done by (Haghighat \& Yazdannik, 2015) who noticed that the majority of the studied nurses adjust the suctioning pressure correctly, and about two thirds of the nurses allow suction interval $\leq 1$ minute. In relation to activities after suctioning, the present study demonstrated that three quarters of the study nurses not made reassessment of the patient respiratory system after the procedure, two thirds of them not hyper oxygenate the patient after the procedure but all of them document the procedure and its notes. These results were matched with the results of (Haghighat \& Yazdannik, 2015) who found that $95 \%$ of the staff nurses not make reassessment of the patient and all of them document the procedure correctly.
Concerning to safety preparation for intubated patient, the current study illustrated that all of the nurses in the control group check the correct ETT placement, monitor $\mathrm{ABG}$ and mechanical ventilator mode and parameters and this result is in accordance with (Parker, 2016) who report that the nurses must check the ventilator mode and parameters. About two thirds of them don't use aseptic technique in suctioning of the patient and all of them can't check the causes of the mechanical ventilator alarms and this result disagrees with (Blot et al., 2018) who showed that the nurses must be aware about the alarms of the ventilator and its management.

As for infection control measures, the present study reported that more than half of the nurses don't made hand washing between contacts with different clients, more than two thirds of them do hand washing before any invasive procedure and this study disagree with (Parker, 2016) who noticed that about two thirds of nurses had poor practice regarding to hand washing before and after hand washing.

In relation to gowning, the present study showed that more than three quarter of the nurses remove gowning and perform hand washing incorrectly and this result disagree with (Rouze, et al., 2018) who found that all of nurses of this study wear and remove the gown correctly.

The current demonstrated that more than two thirds of nurses don't wash the perianal area and half of them place water proof under the patient, and all of them assess the meatus for discharge and dispose equipment with removing gloves. These results agree with (Yakusheva, et al., 2019) who noticed that more than three quarters of the studied nurses assess the meatus for discharge put lubricant on the tip of catheter and observe the color amount and presence of pus in urine.

The present study revealed that about of the nurses monitor the weaning parameters effectively and plan to initiate the weaning procedure early in the day but they didn't explain the weaning to the patient. This result is consistent with the result of (Shehab, et al., 2018) as regard for parameters assessment and starting at the day but disagree with (Gad, 2016) who noticed that all of the study nurses communicate with patients about the weaning process.

As regard to the checklist of $\mathrm{ABG}$ specimen, the present study showed that all of the studied nurses didn't perform Allen's test and more than four fifth of them record the delivered oxygen concentration but about half of them don't clean the patient skin before puncture. This result disagrees with (Youssef, et al., 2018) who three quarters of the studied nurses clean the puncture site and perform Allen's test before the specimen collection. 
In relation to the total practice for the study nurses, the present study represents that about two thirds of the group had low level of total practice, more than one quarter had moderate level of practice and about $10 \%$ of them had a higher level of practice. In contrast, (Alghamdi, et al., 2018) showed that the total score of nurses' practice revealed that less than half $(46.7 \%)$ of intensive care unit (ICU) nurses have adequate practice and $40 \%$ have inadequate practice. In relation to socio-demographic data and total practice score, the current study demonstrated that there was a statistically significant difference related to training courses and increasing the level of practice. In the current study illustrated that nurses more than 25 years old, level of education, and years of experience increasing the total practice score and these results is in the same line with (Feroze, et al., 2017) who reported similar results.

\section{Conclusion}

It was found that more than half of nurses $(60.0 \%)$ were low, $(30.0 \%)$ of them were moderate and $(10.0 \%)$ were high.

\section{Recommendations}

- Nurses need in -service training programs to improve the practice of health care professionals and provide high quality care

- Periodic monitoring of nurses practices and effective training for new nurses.

\section{References}

1. Alghamdi M., Ghaleb M., \& Elmetwaly S., (2018): Assessment of Intensive Care Nurse Knowledge and Perception of Eye Care Practice for Unconscious and Mechanically Ventilated Patients in Intensive Care Units in Saudi Arabi, Journal of Nursing and Health Sciences, 4(1):15-23.

2. Amr A., \& Mohsen S., (2017): A comparative study between the bispectral index and the clinical score in the evaluation of sedation level in critically ill, mechanically ventilated patients, Research and Opinion in Anesthesia \& Intensive Care, 4(2): 77-83.

3. Bayoumi M., \& Mahmoud N., (2017): Effect of education program on nurses' knowledge and practice regarding care of central venous line in pediatric hemodialysis: evidence-based practice guidelines, Egyptian Nursing Journal, 4(2):8799.

4. Blot S., Vandijck D., \& Labeau S., (2018): Oral Care of Intubated Patients, Clinical Pulmonary Medicine, 15(3):153-160.
5. Carruthers H., Gomersall Tand Astin F., (2018): The work undertaken by mechanically ventilated patients in Intensive Care: A qualitative meta-ethnography of survivors' experiences, International Journal of Nursing Studies, Elsevier, 86:60-73.

6. Gad N., (2016): Efficacy of implementing nursing care protocol on the incidence of ventilator associated pneumonia in intensive care unit at Tanta emergency hospital, Journal of American Science 12(2):40-52.

7. Guilherme S., \& Martin K., (2017): Weaning from Mechanical Ventilation, Assisted Ventilation of the Neonate, $6^{\text {th }}$ ed, Elsevier Inc, pp 243-250.

8. Feroze M., Afzal M., Sarwar H., Afshan S., \& Gilani S., (2017): Assess Knowledge and Practice of Registered Nurses about Patient Safety after Cardiac Catheterization in Punjab Institute of Cardiology Hospital, Lahore Pakistan Journal of Medical and Health Sciences, 2(22).

9. Haghighat S., \& Yazdannik A., (2015): The practice of intensive care nurses using the closed suctioning system: An observational study, Iranian Journal of Nursing and Midwifery Research, 20(5)619-625.

10. Hakim A., (2015): Assessing nurses' performance in endotracheal tube suctioning in Neonatal Intensive Care Units, Iran J Critical Care Nursing, 8(2): 89-94.

11. Hennessey, I., \& Japp, A., (2016): Arterial Blood Gases Made Easy, Elsevier,2016:A Arterial Blood Gases Made Easy(Vol.1) Bukupedia.

12. Hetland, B., Heusinkvelt, J., Krabbenhoft, L., \& Grotts, E., (2018): Mechanical ventilation weaning: An evidence-based review. Nursing2018 Critical Care, 13(6), 5-16.

13. Lesley M., \& Sandeep S., (2019): Issues of Concern, Ventilator Safety, National Library of Medicine.

14. Lindgren A., \& Ames N., (2015): Caring for patients on mechanical ventilation: what research indicates is best practice, The American Journal of Nursing 105(5):50-60.

15. Khalil N., Youssef W., \& Mohamed A., (2018): Patients' weaning from mechanical ventilation: Complete versus incomplete ventilator bundle implementation, International Journal of Africa Nursing Sciences, (8):28-32.

16. Mehdi M., \& Claude G., (2018): Effects of patient positioning on respiratory mechanics in mechanically ventilated ICU patients, Annals of Translational Medicine, 6(19): 384. 
17. Mohamed A., Mohamed W., \& Ali N., (2017): Effect of ventilator bundle implementation on weaning indicator among mechanically ventilated patients at a selected private healthcare sector, Egyptian Nursing Journal, 14(1): 50-57.

18. Mwakanyanga E., Golden M., \& Edith A., (2018): Intensive care nurses' knowledge and practice on endotracheal suctioning of the intubated patient: A quantitative cross-sectional observational stud, PLoS ONE, 13(8).

19. Osti, C., Wosti, D., Pandey, B., \& Zhao, Q., (2017): Ventilator-Associated Pneumonia and Role of Nurses in Its Prevention. Journal of the Nepal Medical Association, 56(208).

20. Parampreet K., Claire R., Gregory S., \& Kevin R., (2019): Dangers of Peripheral Intravenous Catheterization: The Forgotten Tourniquet and Other Patient Safety Considerations, Vignettes in Patient Safety, Intech Open.

21. Parker C., (2016): Ventilator settings and modes, Top 10 care essentials for ventilator patients, American nurse today journal, 7(3).

22. Powers J., (2016): Two methods for turning and positioning and the effect on pressure ulcer development:acomparison cohort study.Journal of Wound Ostomy\&Continence Nursing, 43(1),46-50.

23. Richard B., Timothy G., Joy H., Peter P., Dario R., (2016): safe initiation and management of mechanical ventilation, American Association for Respiratory Care 84(5),60-65.

24. Romero C., Budini H., Cerpa F., Caceres D., Hidalgo V., (2015): Pathophysiological Basis of Acute Respiratory Failure on Non-Invasive Mechanical Ventilation, Open Respiratory Medicine Journal, 9: 97-103.

25. Rouze A., Martin I., \& Nseir S., (2018): Airway Devices in Ventilator-Associated Pneumonia Pathogenesis and Prevention. Clin. Chest Med, 39(4):775-783.

26. Shehab M., Saadoon M., Nasser N., \& Fathy A., (2018): Nurses Performance about Safety Weaning from Mechanical Ventilation of Critically Ill Adults and Children, international journal of nursing didactics, 8 (11).

27. Xiao Li \& Fan J., (2015): A care bundle for pressure ulcer treatment in intensive care units, International Journal of Nursing Sciences, 2(4): 340-347.

28. Yakusheva O., Costa D., Bobay K., Parada J., \& Weiss M., (2019): Variability in catheterassociated asymptomatic bacteriuria rates among individual nurses in intensive care units: An observational cross-sectional study, PLoS one journal 14(9),40-50.

29. Youssef W., Ahmed Y., Shabaan N., \& sameh E., (2018): factors affecting validity of arterial blood gases results among critically ill patients: nursing perspective, journal of education and practice, $4(15): 43-56$. 